\title{
Lean And RFID: Friends Or Foes?
}

Anthony L. Patti, Macon State College

Anthony Narsing, (Email: anthony.narsing@maconstate.edu), Macon State College

\begin{abstract}
The Lean Manufacturing principles and methodology seek to eliminate waste from systems. Many of the lean techniques emphasize simplicity. For example, 5S (sort, set in order, shine, standardize, and sustain) and visual workplace management strive to organize and maintain the workplace so that it is easy to identify, find, and count items. Visual signals such as Kanbans are used to time the movement of inventory. The most basic utility of radio frequency identification (RFID) is to provide timing and location information. Most RFID systems provide data that indicates when an item has passed by a reader. As long as it is known where the reader was at the time of the read, location information is also available. Readers are placed strategically so that after the read, the item's location is known to be within a defined area. Additionally, real time locator systems (RTLS') use an array of readers to triangulate a more precise location for the item. Implementation of RFID systems is being driven primarily by large retailers and the Department of Defense (DOD). They are requiring their suppliers to attach RFID tags to the items they supply. However, it has been noted that suppliers who just "slap and ship" tags will find RFID to be an added expense. Suppliers who use RFID tags to improve their inventory and production management will find RFID to be an investment with a fairly short payback. This article will explore the relationship between RFID and Lean Manufacturing. Are RFID and Lean competitive or compatible? Does RFID improve Lean systems or do Lean systems improve RFID?
\end{abstract}

Keywords: RFID, Lean, Operations Strategy

\section{INTRODUCTION}

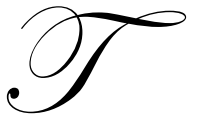

here are a plethora of tools, techniques, technologies and philosophies available to assist business managers in improving their resource management. Arguably, few have received as much attention as Lean and Radio Frequency Identification (RFID). Lean is a philosophy that fosters continuous improvement within an organization by systematically identifying and eliminating all forms of waste. RFID is a technology that allows items to be "tagged" with a device which can be read electronically. The information provided by the tag can range from a simple identification number to much more complex configuration and environmental history data.

This article seeks to explore the relationship between Lean and RFID. Are they compatible with one another? Should firms implement one instead of the other or should they implement both concurrently? The rest of this article unfolds as follows. First, brief descriptions of Lean and RFID are presented. Next, the relationship between Lean and RFID is explored by examining where RFID can be used to identify and eliminate the various forms of waste. The article concludes with some discussion as to how firms should view the adoption of Lean and RFID.

\section{LEAN}

There are various definitions of Lean floating around (see for instance the Womack, Jones, and Roos, 1991; Liker, 2004). In general, most define Lean as the continuous and persistent pursuit and elimination of waste in all of the processes that make up the enterprise. As waste is removed, manufacturing, service, and administrative systems become more efficient at providing products and services as needed, when needed, and where needed with a 
minimal amount of resources. Lean manufacturing has its roots back in the Toyota Production System (TPS). TPS is largely attributed to Taichi Ohno. In the 1950's Ohno was tasked by Eiji Toyoda with improving Toyota's production system. Ohno and other Toyota managers visited U.S. automotive facilities expecting to learn more about what they needed to do. Instead, they learned many things they should not do. To a group of managers from a firm with minimal resources (equipment, space, and money) and low volume demand, many of the things they saw in U.S. plants looked very wasteful. They saw large batches of parts being run on massive machines and then moved to a storage area to await the next process. Later, the large batch of parts was moved to the next process and the cycle repeated.

Interestingly, one thing they saw in the U.S. that did make sense and ultimately had a major impact on the TPS was grocery stores. There they saw customer demand driving the replenishment of products. Items on the store shelves were only replaced after someone purchased one. Thus, inventory levels were held constant. This became the basis for a "pull" type production system as opposed to the traditional "push" systems employed at the time. Over time many have studied and written about the TPS. In 1990, Womack, Jones, and Roos wrote a book entitled The Machine that Changed the World. In that book they coined the phrase "lean manufacturing" to describe the TPS. Today, many have shortened the phrase to simply "lean". In addition to being more concise, this simplification is appropriate since the concepts of lean are successfully being used in areas other than manufacturing.

While developing the TPS, Ohno identified seven types of waste. The concept behind the TPS was to identify and eliminate these wastes. The seven wastes are:

\footnotetext{
- $\quad$ Over production ahead of demand

- Waiting for the next process step or information

- $\quad$ Transporting materials unnecessarily

- $\quad$ Over and non-value added processing (gold plating)

- Inventory that is more than bare minimum

- Motion by employees that is unnecessary

- $\quad$ Producing non-conforming parts
}

Later in this article we will discuss how RFID may or may not be useful in identifying and eliminating these wastes. Thus, it is useful to briefly describe what is meant by each of these.

\section{Over Production Ahead Of Demand}

Producing an item before it is needed requires the firm to purchase material before it is needed. As that material moves through the system from raw material to work in process (WIP) to finished goods, consumes resources such as space, labor, and cash. Even though it may be necessary in some cases (i.e. where there are uncontrollable demand fluctuations and capacity is mostly fixed), it is still a waste.

\section{Waiting For The Next Process Step Or Information}

Resources that sit idle waiting for material, information, or approvals are being wasted. Ohno and his team saw large batches of materials queued up in front of workstations waiting their turn to be processed. In effect, this represents over production. If the succeeding process is not ready to work on the job, the previous process produced the job before it was demanded.

\section{Transporting Materials Unnecessarily}

Disconnected processing steps often lead to unnecessary transportation of material. As described earlier, one of the things Ohno observed was large batches of material processed at a step and then moved to a centralized holding area. When the next step in the process was ready, the material was retrieved from the central storage area and then put back when the processing was complete. A leaner system would move the material just finished at step 
one directly to step two; bypassing the central storage area. Furthermore, the material would arrive at step two justin-time (JIT).

\section{Over And Non-Value Added Processing (Gold Plating}

Value must be defined from the customer's perspective. If you are doing something for which your customer is willing to pay, you are adding value. Extra product features, performance levels, and even durability levels beyond which the customer desires are wasteful.

\section{Inventory That Is Above The Bare Minimum}

Accountants consider inventory an asset. Assets are normally considered to be good things. However, inventory is not. Inventory is expensive. Space, storage equipment, insurance, taxes, and obsolescence are just a few of the costs of carrying inventory. Perhaps the single highest cost is borrowing costs. If a firm is borrowing money at 10 percent, every $\$ 100$ tied up in inventory costs $\$ 10$ just to pay for the interest. And the costs go up from there.

\section{Motion By Employees That Is Unnecessary}

A common practice in facility design is to have a centralized location for parts and/or tooling. This requires workers to leave their areas and travel to these locations to retrieve necessary equipment and supplies. The lean solution is to locate parts and tools at their point of use

\section{Producing Non-Conforming Parts}

A very obvious form of waste is producing non-conforming parts. These parts have to be either reworked or scrapped. Furthermore, a system with persistent quality problems will either have to carry higher levels of "justin-case" inventory or accept higher levels of idle resources. It is important to understand that lean is more than a simple collection of tools and techniques. If that was all there was to it, many more companies would enjoy Toyota's success. Rather, lean is more of a management philosophy that emphasizes processes, people and partners, and problem solving (Liker, 2004). In a later section we will discuss how RFID fits with lean's mission of identifying and eliminating waste. However, before that, we need to discuss the capabilities and constraints of RFID.

\section{RADIO FREQUENCY IDENTIFICATION (RFID)}

RFID tags consist of two principal components: a silicon microchip and an antenna. The chip can perform two functions: receive and transmit data. Tags can be classified as active, semi-active or passive. Passive tags are by far the simplest and least expensive which makes them economically attractive to users. They have no power source as they obtain energy from the radio frequency field emitted by the reader. Semi-active or passive tags have an energy source built onto the micro-chip hence adding to its cost. However, they have the ability to provide a broad range of coverage and to also read information from sensors (Lawrence, 2004).

A typical operation of an RFID occurs when a reader uses a coiled antenna to create a magnetic field which reaches the chip on a passive tag regardless of its position or orientation on the shelf or floor. The microchip is energized by the radio frequency field and subsequently transmits data via its antenna containing product information such as batch number, production date and so forth. Multiple tags can be accessed by a reader which can vary from a hand-held device to a stationary tunnel like device able to scan boxes on a conveyance system. The reader must be within acceptable distance. Readers are strategically positioned at various locations such as by dock doors, pallet racks, conveyors or check out lanes (Kinsella, 2003). 
Broadcasting frequencies for RFID systems vary. Low frequency application can range from $3 \mathrm{KHz}$ to 300 $\mathrm{KHz}$ while high frequency applications range from $3 \mathrm{MHz}$ to $30 \mathrm{MHz}$ (Bednarz, 2002). Very high frequency (VHF) ranges from $30 \mathrm{MHz}-300 \mathrm{MHz}$ and ultra high frequency (UHF) ranges from $300 \mathrm{MHz}-3 \mathrm{GHz}$. Different frequency ranges have different antenna, power consumption, data rate, and propagation characteristics.

As with many technologies, there are always limitations. RFID technology has a number of operational factors which can adversely impact its efficient operation such as RFID command language, the presence of moisture, inclement weather, radiation, invisible RF interference (i.e., WLANs), attenuation, reflection and refraction of radio waves, the material to which a tag is affixed and to some extent building material content (Goldman, A. and Crawford, K., 2004). Global operating standards remain a contentious issue. For instance, countries that use different operating standards create tremendous barriers to global integration. Regulatory laws in Asia, Europe and North America are specific regarding frequency and power requirements (Bednarz, 2003). For instance, for UHF tags, Asia uses $950 \mathrm{MHZ}$, Europe uses $869 \mathrm{MHZ}$ and North America uses 915 MHZ. Japan refuses to allow UHF RFID applications. Interestingly enough, Gillette had purchased 500 million tags at less than 10 cents only to find out that these tags were not compliant with European standards. They are currently testing tags from Phillips to determine their applicability overseas. There are three major international RFID standards floating around. They are ISO/IEC18000, EPCglobal and UbiquitousID (China Tech News, March 31, 2006). The lack of a single standard is causing at least some countries (i.e. China) delays in adopting national standards. EPCglobal has won the support of WalMart with its Generation 2 (GEN 2) standard. EPCGlobal that was introduced in December of 2004. A similar standard for HF tags is currently being developed (XTVWorld, May 5, 2006).

Basic RFID systems do not inherently provide item location information. All that is really known about an item's location is that it was within the read range of a particular reader at a specific time. What happens to the item after that is unknown. Certainly, many users strategically place readers at all entry and exit points to a defined area and thus, can reasonably accurately assert that an item is either in or out of that area. However, without strict attention to system design and movement procedures, it may be possible to relocate items without the system knowing. However, specially designed RFID based systems known as real time locator systems (RTLS) can provide robust location information to within several feet. These systems use an array of antennas and/or readers to keep track of inventory items in real time. Active RFID tags are needed. However, in most applications the tags are reusable. This helps keep the cost of such systems more reasonable.

\section{NEW KNOWLEDGE, NEW TECHNOLOGIES, AND BUSINESS STRATEGY}

Emerging technologies and knowledge offer companies the opportunity to rethink what are now tradeoff decisions and give customers more of what they want. For example, before the internet, firms had to make tradeoff decisions between cost and responsiveness when it came to transferring information. A firm could send a report via regular mail for a low price but it may take several days to reach its destination. Or, the company could send the report via an over-night delivery company but pay a higher price. There was a tradeoff between cost and responsiveness. With the internet you get both lower costs and higher responsiveness. Adopting new knowledge can have the same impact as adopting new technologies. Firms that learn how to properly use tools and techniques that enable them to constantly improve the efficiency and effectiveness of their operations will also be able to offer higher levels of customer service and lower their costs. However, firms have to be careful here. Adopting new technologies and/or new knowledge that does not fit with the firm's competitive strategy can prove ineffective and even detrimental.

A well known case often used in operations strategy classes is "The Great Nuclear Fizzle at Old B\&W" (see for instance Hill, 2000). One of the points made using this case is how operations decisions must be aligned with the business strategy. B\&W made capital resource, location, and human resource decisions for their new nuclear pressure vessel division the same way they had made them for their very successful steam pressure vessel division. They focused on getting the cost per unit as low as possible and the volume as high as possible. This is what had made them so successful in the steam pressure vessel industry. However, the nuclear pressure vessels were in the introduction stage of their product life cycle while the steam pressure vessels were in the mature stage. As with any introductory technology, constant design and process changes were a matter of reality. Unfortunately, 
the high volume processing equipment that was needed did not exist and had to be designed. In effect, B\&W chose to pursue product design and process design at the same time. This is a very risky strategy considering changes in their product design could necessitate a change in the process design. The installation of some of the necessary processing equipment was delayed by more than a year. Furthermore, B\&W located the facility way out in the country because of the availability of low cost land, low wage demands, and a river that would make transporting the finished product less expensive. Unfortunately, the skill level needed for these new pressure vessels was far beyond what was available in the area. B\&W had trouble hiring the people they needed and the quality of the product suffered. In the end, the new division fell way behind on their delivery schedule and a group of their customers took them to court to have the vessels that were in process taken away and given to competitors to complete. The core problem at $\mathrm{B} \& \mathrm{~W}$ was a lack of knowledge. The managers who made these decisions failed to understand the vital link between business strategy and operations decisions. They only knew what had worked for them in the past; but not why. Thus, they could only copy what had worked.

For our discussion here, there are two important takeaways from this case. First, firms must adopt new knowledge. All of the managers and workers in a firm should often (if not constantly) be reading and learning about world class leaders and what it is that makes them world class. This should not be limited to just their industry. No matter in what industry managers work they should be reading about Wal-Mart, Federal Express, Ritz Carlton, Sewell Cadillac, Southwest Airlines, and, of course, Toyota. Sewell's tenth commandment of customer service is "Japanese them: Learn how the best really do it and then make their systems you own. Then improve them" (Sewell \& Brown, 1990). The other takeaway is that adopting new knowledge and new technologies outside of a comprehensive business strategy that defines and details who you are and who you are not is dangerous. One of the authors here once interviewed a manager in a company that was known for incredible responsiveness to customer needs. They had very short lead times for their products and $99.97 \%$ due date reliability. When they promised customers that their order would be shipped, customers knew it would be shipped. The promise was also backed-up with a $\$ 10,000$ credit if the order did not ship when they said it would. Being that responsive required them to carry some extra inventory. The manager being interviewed described how several years back they had hired a new manager in operations who had a lot of just-in-time (JIT) experience. Unfortunately, when that manager started emphasizing lowering inventory to JIT levels, the company started missing due dates. That manager did not last very long.

To summarize, new knowledge and new technology can propel companies into leadership positions within their industries. Providing more value to the customer while simultaneously lowering costs allows a company to capture more market share with lower prices or achieve higher profit margins with differentiated pricing. However, new knowledge and new technologies must be properly integrated into the firms overall competitive strategy. In the next section we discuss lean and RFID in this context.

\section{LEAN AND RFID}

The goal of this article is to explore the relationship between lean and RFID. Early on we asked two questions. Are lean and RFID compatible with one another? Should firms implement one instead of the other or should they implement both concurrently? We asked the questions this way because we believe these are the questions facing many managers. We now look to answer these questions. In the context of our previous discussion on knowledge, technologies, and business strategy, lean is a management philosophy and represents new knowledge. Note that this view of lean requires one to view lean as more than just a collection of tools and techniques (Liker, 2004). Lean is a philosophy of long term thinking that drives the continuous pursuit and elimination of waste. On the other hand, RFID is a new technology (new, that is, from the point of view of a firm that is considering adopting it). RFID has exciting possibilities in a myriad of applications (i.e. warehousing, logistics, healthcare, military, etc.).

As discussed before both new knowledge and new technologies have the ability to burst conventional paradigms and leapfrog companies into leadership positions within their industries. However, adopting either of these outside a comprehensive business strategy can have dire consequences. Thus, it is imperative that managers conduct a formal business planning process where they outline their vision for the future. Specifically, they will 
need to develop a detailed understanding of their internal strengths and weaknesses and the external opportunities and threats they are facing. A specific description of where they want to take the company will allow managers to choose the knowledge and technologies that will help them get there. The generic nature of the lean philosophy makes it suitable for a wide variety of business strategies. The very first step to implementing lean is to identify value (Womack \& Jones, 1996). Value must be stated from the customers' perspectives. Some customers are primarily looking for low prices. Others are primarily looking for high quality or quick responsiveness. In fact, all customers would want all of those things to the extent possible. However, at any one point in time, a tradeoff decision may be necessary. Managers have to understand how their customers want those tradeoff decisions made. Furthermore, managers must continue to look for ways to eliminate the tradeoff and break through the current paradigm. Thus, lean represents knowledge that can be used in virtually any strategic environment. However, without a comprehensive business plan, lean efforts will be unfocused and may or may not contribute to the overall strategy of the firm. A business plan will focus the lean efforts.

As the lean process uncovers waste within firms, it is necessary to identify ways to reduce that waste. This is where RFID may be of assistance. Depending on the type of waste and the nature of the problem, RFID may be part of a comprehensive solution that can be used to reduce the waste. Let's look at some of the ways RFID is being used to eliminate waste and provide more value to customers.

\section{Item Identification}

Perhaps the most often thought-of application for RFID is item identification. Material with RFID devices can be scanned and identified much in the same way a barcode is utilized. The advantage with RFID is that the identifying tag does not have to be visually located. With RFID you simply pass the item (or groups of items) within the field of a reader and the RFID tag is read.

WalMart is recognized as one of the leading proponents of and driving force behind using RFID for item identification purposes. In the summer of 2003, WalMart announced an aggressive timetable for their suppliers to begin attaching RFID tags to shipments. WalMart required their top 100 suppliers to be RFID compliant by January 1, 2005 and their next 200 supplies to be ready by January 1, 2006. At the present time Walmart requires pallet level tagging not individual item level tagging. WalMart reports that it is able to replenish out-of-stock merchandise three times faster for items using RFID than the items using bar-codes. In addition, they have had a 16\% reduction in out-of-stock merchandise (RFID Gazette, Oct. 16, 2005). Other retailers, such as Target and Best Buy, are following WalMart's lead.

The Department of Defense (DoD) is also pushing suppliers to be RFID capable. RFID tags became mandatory as of January 1, 2005 for pallets and cases and individual high dollar items. The DoD adopted the EPCglobal standard in addition to a DoD standard. Suppliers can choose either standard. There is an advantage here for suppliers such as Proctor and Gamble in that they can use the same tags for the DoD as they use for WalMart (Roberti, 2004). The DoD is reporting significant improvements in supply chain visibility and cuts in inventory. Marines in the field can see in real time where their needed supplies are. Instead of asking where their stuff is, they now ask "Why isn't my stuff moving?" The Marine supply chain has been able to reduce its inventory level from $\$ 127$ million to $\$ 70$ million (Collins, 2006). Even using a conservative annual inventory carrying cost rate of 25\%, this $\$ 47$ million reduction results in an estimated $\$ 11$ million - \$12 million annual savings.

An interesting application for RFID's item identification capability is in the automotive industry. AMR Research states that the auto industry spends a staggering $\$ 750$ million each year on lost containers. Since typical assembly plants use hundreds of suppliers and each has their own containers, there is quite a bit of "container confusion." The Automotive Industry Action Group (AAIG) is working on a standard for an RFID enabled reusable tote. In this case, it is not the items in the totes that are necessarily being tagged, it is the tote itself. Even the construction industry is seeing benefits from RFID. RFID has been shown to reduce time and increase the accuracy of the "kick and count" construction site material receiving process Other potential benefits could be gained from smart tags that can carry item information such as quality control documentation, inspection signatures, handling and storage information, and calibration data (Jaselskis \& El-Misalami, 2003). Certainly, these are only a few of the 
applications of RFID for item identification purposes. Many more exists and new applications are constantly being developed. However, these applications do show how companies are using the item identification capability of RFID technology to reduce the wastes in their systems.

\section{Electronic Kanbans}

At least two companies in the automotive industry (Ford Motor Company and AM General) are using RFID to implement an electronic kanban system (Hill, 2004; Witt, 2006). In traditional kanban replenishment systems an inventory worker travels around looking for kanbans. Kanbans are a visual indication that signals a need for parts. The visual indication can be an empty container, an empty bin, a kanban card, or just about any simple visual means of signaling a need. The electronic systems used by Ford and AM General signal the need to replenish using RFID tags that are configured as "call buttons." When a worker in an area sees that inventory of a specific item has dropped below a certain, specified quantity, he/she presses the call button associated with that item. The RFID device sends information to a server which then processes and sends a pull order to a picker. The picker is notified of the need by a computer screen mounted on their forklift. They then retrieve the item from stock and deliver it to the designate location. This eliminates the need for someone to walk around looking for and collecting kanbans. The shorter replenishment cycle also allows for lower reorder points and thus, lower inventory levels. Over production ahead of demand is also reduced since the supplying process is being paced by the using process.

\section{Item Location (RTLS)}

Real-time-locator systems (RTLS) can pinpoint an item's location to within several feet in real time. This capability is being used in the automotive industry for tracking parts and in yard management applications at logistics operations. Ford uses active RFID-based RTLS to track the thousands of parts headed for their assembly lines. Traditional systems only inform managers about what they have but not where it is. Location knowledge helps managers make sure parts will be where they need to be when they need to be. This in turn allows Ford to reduce inventory levels and become leaner (Witt, 2006). NYK Logistics uses RTLS in its Long Beach, CA facility. The facility receives containers from 11 different steam ship lines and dispatches them around the U.S using 15 different domestic carriers. There are 1100 parking spaces and 250 dock doors in the facility. When a container arrives a battery-powered RFID tag is attached. Using the RTLS, any container in the yard can be located to within 10 feet. This has greatly reduced the amount of labor required to run the yard and significantly reduced "hunt" time.

\section{CONCLUSIONS ON ADOPTING LEAN AND RFID}

The three RFID applications discussed above (item identification, electronic kanbans, and item location) are but a few ways in which RFID can be used to help reduce waste. They illustrate how RFID is being used to limit over production ahead of demand, waiting, unnecessary transportation, inventory, and unnecessary motion by employees. Thus, RFID can coexist with lean and help with lean implementations. However, management must take care to not jump on the RFID bandwagon without a comprehensive business strategy that will likely include some form of continuous process improvement; lean or otherwise. It is the process improvement activities that should look at current operations and identify waste. Projects that will reduce waste can then be prioritized and funded. Where appropriate, RFID can be considered. It should also be noted that a technology like RFID can be of benefit across many waste reduction projects. Thus, when prioritizing projects it may not be appropriate to view projects in isolation (i.e. project 1 versus project 2 versus project 3). The startup costs of RFID can be high. However, once the infrastructure is in place, new applications may only require a marginal investment.

\section{REFERENCE LIST}

1. Settles, P. and Grasso, J., EPC Global Forms New Standards Work Group, XTVWorld, Available from internet: http://press.xtvworld.com/article11258.html, May 5, 2006, (cited June 12, 2006).

2. $\quad---$, China Will Soon Promulgate RFID Standard, China Tech News, Available from internet: http://www.chinatechnews.com/2006/03/29/3570-china-will-soon-promulgate-rfid-standard/, March 30, 2006, (cited June 12, 2006) 
3. ---, RFID at Wal-Mart, RFID Gazette, Available from internet: http://www.rfidgazette.org/2005/10/rfid at walmart.html, October 16, 2005, (cited June 12, 2006).

4. Bednarz, A., Wireless Technology Reshapes Retailers, Network World, Framingham, v.19, Issue (32), p.23-24, (2002).

5. Collins, Jonathan, DOD Quantifies Payback from RFID, RFID Journal, Available from internet: http://www.rfidjournal.com/article/articleview/2313/1/1/, May 3, 2006, (cited June 12, 2006).

6. Goldman, A. and Crawfor, K., Five Myths Exposed, Tech Centre, USA, (2003).

7. Hill, Sidney, The other Use of RFID, MSI, Vol. 22, No. 9, (Sep 2004), pp. 46.

8. Hill, Terry, Manufacturing Strategy: Text and Cases, McGraw-Hill (2000).

9. Jaselskis, Edward J., and Tarke El-Misalami, Implementing Radio Frequency Identification in the Construction Process, Journal of Construction Engineering and Management, Vol. 129, No. 6, (Nov/Dec, 2003), pp. 680-688.

10. Kinsella, B., The Wal-Mart Factor, Industrial Engineer, Norcross, v.11, Issue 11 (2003), p.32-36.

11. Lawrence, D., Tracking RFID Progress, American Printer, Chicago, v.232, Issue (4), p.16-17 (2004).

12. Liker, Jeffrey K. The Toyota Way, McGraw-Hill (2004).

13. Roberti, Mark, DOD Releases Final RFID Policy, RFID Journal, Available from internet: http://www.rfidjournal/article/articleview/1080/1/1/, August 9, 2004, (cited June 12, 2006).

14. Sewell, Carl, and Paul B. Brown, Customers for Life: How to Turn that Onetime Buyer into a Lifetime Customer, Doubleday (1990).

15. Witt, Clyde E., Real-Time Part Tracking and Replenishment, Material Handling Management, Vol 61, No. 4, (Apr 2006), pp 39-42.

16. Womack, James P. and Daniel T. Jones, Lean Thinking: Banish Waste and Create Wealth in your Organization, Free Press (1996).

17. Womack, James P., Daniel T. Jones, and Daniel Roos, The Machine That Changed the World, Macmillan Publishing Company (1990).

\section{NOTES}

